\title{
Design Strategies for Safer and More Inclusive Public Spaces
}

\author{
MARIA ANTON-BARCO \\ ESNE University School of Design, Innovation \& Technology
}

Public space in the city is being continuously contested. The most compelling of these challenges comes from the recent terrorist attacks on cities across the world. While the awareness of the need to 'design against terrorism' and a demand for greater safety in public spaces has entered into citizen's consciousness -given the perception of fear due to recent attacks- drastic security and surveillance measures usually go against a more open and inclusive public realm.

Whereas some initiatives have proven successful to prevent these attacks, security measures imposed upon citizen's can also detract from public spaces, discouraging gatherings, eliminating services, or even making public space more dangerous. Many cities are trying to tackle this issue; thus, their initiatives have proven to be extremely restrictive: jersey barriers, bollards, restricted areas, CCTV cameras, and security guards are the most common measures taken and they have transformed public space in many cities. In some cases, bollards are decorated or painted in an attempt to softer their impact or disguised as planters.

Furthermore, new guidelines and rules have appeared in the last years, and the European Union has established security as a new strategic objective. However, there's a critical component to these new security landscapes that has not been addressed: making people feel safe without having them feel like they are constantly living under threat.

Focusing on London, New York and Madrid -all of them recent terrorist targets - the purpose of this paper is to identify design strategies that make public space safer, especially against unsophisticated low-tech attacks, preserving the openness of these spaces and the ability of citizens to gather and move freely about the city.

This paper aims to catalogue and analyze security landscapes providing an empirical grounding to a future Guide of Good Practices for Urban Security in the global West.

\section{INTRODUCTION}

The topic of 'urban safety and security' covers a wide range of concerns and issues. These span from basic needs such as food, shelter and health, through impacts of natural disasters, to collective security needs, such as protection from urban terrorism or war. ${ }^{1}$
These two last issues are getting more attention since $9 / 11$, although terrorism and war have been a constant in the urban context since the Middle Ages. But, as Stephen Graham states, for the first time since that era the localized geographies of cities are starting to dominate discussions surrounding war, geopolitics, and security. ${ }^{2}$

The rapid urbanization of the world matters profoundly. The way cities grow in developed and developing countries is critical. While relatively egalitarian cities like those in continental Western Europe tend to foster a sense of security, highly unequal societies are often marked by fear, high levels of crime and violence, and intensifying militarization. Maps shown how terrorism in not an exclusive issue of developed or undeveloped countries, but rather a global problem that should be globally addressed. For example, figure 1 shows a map that includes terrorist attacks on public spaces and infrastructure.

Due to the current situation, cities such as Madrid, Barcelona, London, Boston or New York, among many others, have made changes on their streets trying to tackle this issue. However their initiatives have not yet prove to be successful and seem to be orientated towards providing citizens with a greater sense of security.

Nonetheless, unnecessary or too drastic security measures can erode people's right to access public spaces, exploit fear and insecurity and even promote exclusion and unequality. In fact, this sense of vulnerability leads decision makers and politicians to increase even more security measures, creating a vicious cycle in which more is always perceived as better, and degradating the urban realm. Thus, there's a critical component that should also be addressed: is it possible to make people feel safe without having them feel like they're constantly living in a high-threat terrorism zone.

The purpose of this research is to identify design strategies to make public space safer, especially against unsophisticated lowtech attacks, while preserving the openness of this spaces and the ability of citizens to gather and move freely about the city.

The issue we tackle today is: at a time when concerns for public safety mix with a desire to see fewer controlled and regulated urban places, how is the nature of public space in European and Western cities changing? What's improving and what's getting worse? Are there already any good practices when addressing security in public spaces? 


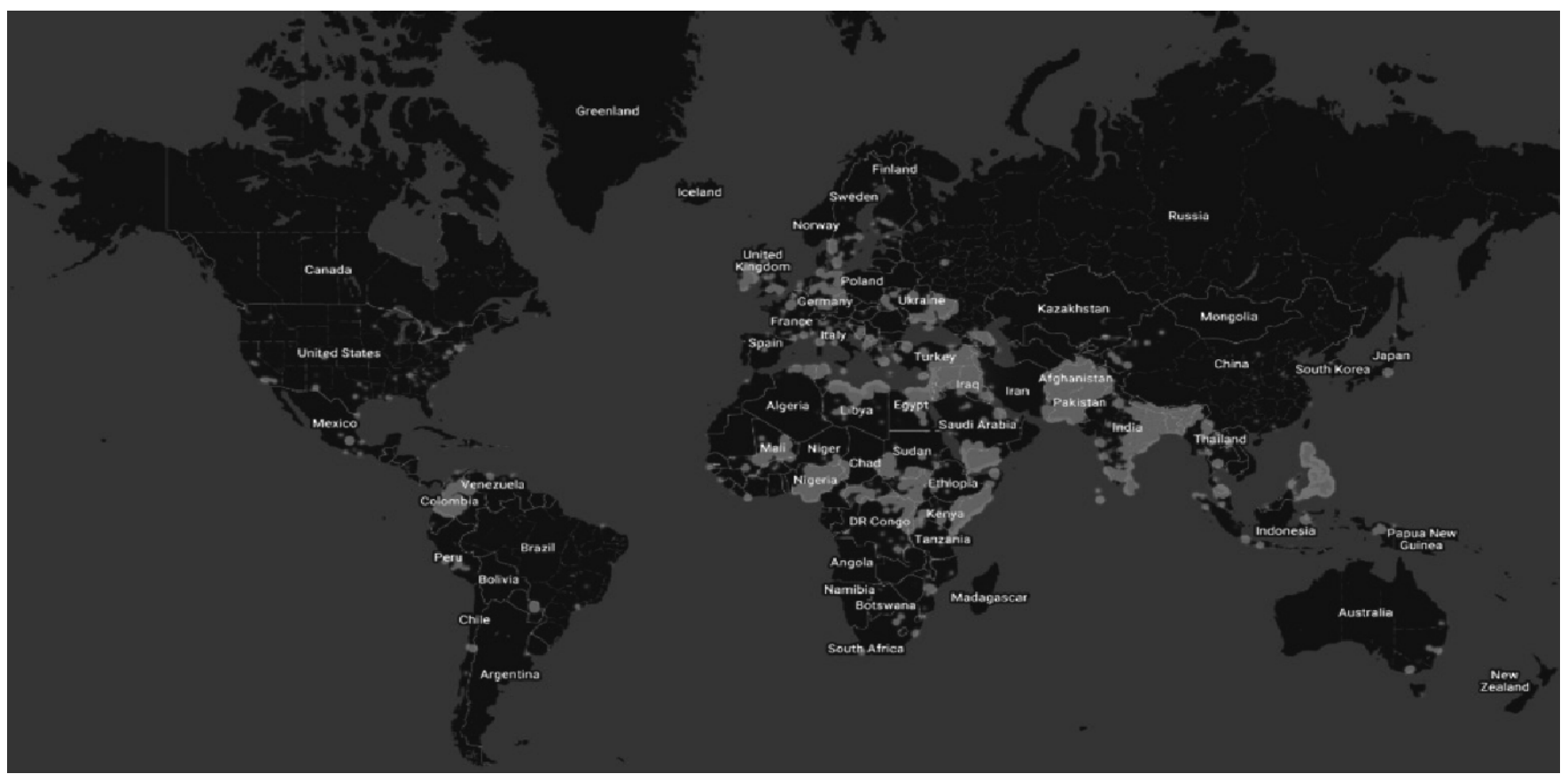

Figure 1: Terrorist attacks and their fatalities in 2016. Source: Business Insider.

\section{PHISICAL AND DIGITAL TURN}

As it has been previously stated terrorism is not a new phenomenon. Many countries have suffered it for decades from different groups -both internal and external and including both State and non-State actors- exercising violence against civilians as political strategy. To protect them city walls have been a constant from 3000 b.c. to the XIX-C and some voices argue that Belfast in the 1970's can be identified as one of the first case studies from the modern era. ${ }^{3}$

Nowadays, war has become once again the dominant metaphor when addressing cities and urban societies -at war against crime, insecurity, drugs, corruption and terror-. Thus, new doctrines of perpetual war transform citizens into perpetual targets whose innocence, rather than being assumed, needs to be continually demonstrated.

This modern wish for security has also been manifested in ways that alter the urban landscape. In this respect, two principle movements are readily identifiable. One of them is physical relies the creation of exclusive spaces and deterrent architecture, such as jersey barriers to prevent car attacks or spikes to prevent people from sitting down in certain places.

A second one, more intangible and technology-based has resulted in a tendency to install computerized surveillance cameras or use drones to target and identify users and menaces.

These two strategies bring military ideas to day-to-day city life. Thus, a paradox occurs: techniques that have been deployed for new military urbanism in foreign war zones are used in Western cities. The construction of "security zones" around financial centers and government districts ore buildings directly import the techniques used at overseas bases and green zones ${ }^{4}$. Hard military-style borders, fences and checkpoints appear around these enclaves. Territorial control is central to securitization of urban space. Jersey-barrier blast walls, check points, computerized CCTV systems, biometric surveillance proliferate within the city center, creating borders similar to those between nations.

\section{TERRITORIAL FORMS OF DOMINATION}

The military tasks of tracking, surveillance and targeting do not require completely new technological systems. Instead, they appropriate the systems that already exits and operate. For example in London new CCTV camera surveillance systems use the already existing cameras installed during the 1999 "Ring of Steel."

Spatial tactics of control are by-products of the militarization of policing and the securitization of urban space. Neoliberalist protest policing innovation has led to new modes of tactical spatial engagement, working to strategically nullify political dissent through manipulation of urban space ${ }^{5}$. This has significant consequences for urban design and emergent urban form, particularly through the professional practice of CPTED, or Crime Prevention Through Environmental Design. However this discipline seems to foster an over controlled society.

At the same time, political protest is an increasingly frequent occurrence in urban public space. The urban realm is essential in the functioning of democratic politics. It is the place of citizenship and it allows people to interact and have a sense of identity and community. It should play host 


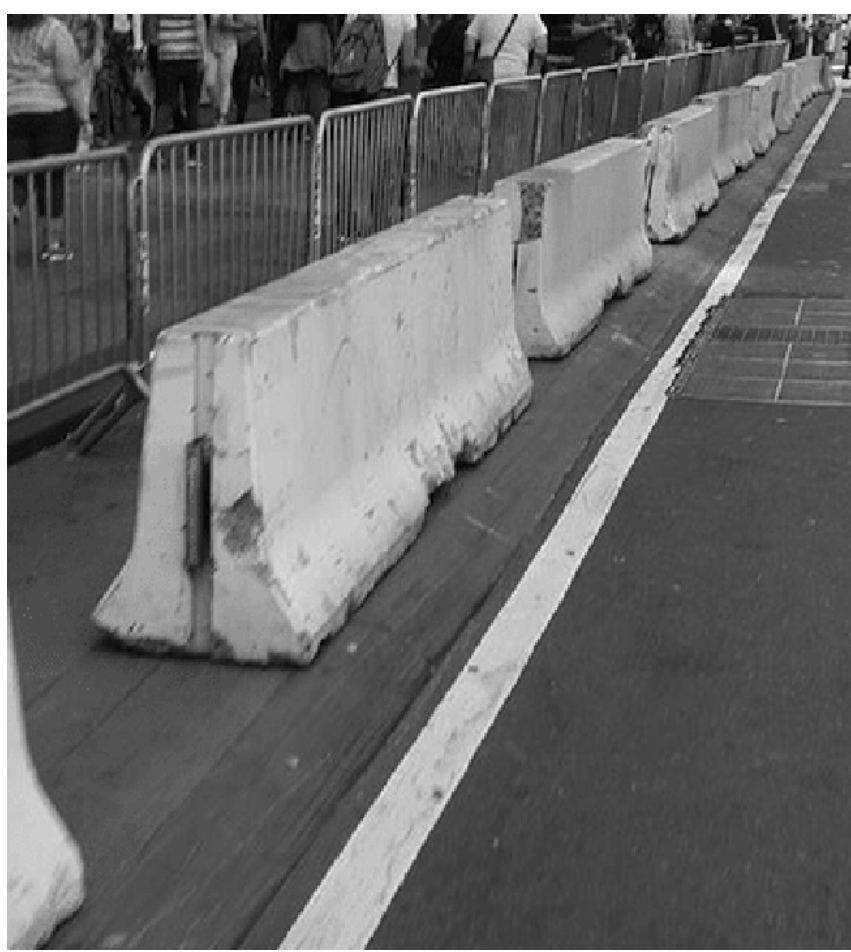

Figure 2: Jersey barriers located in NY times Square bike lane. Source: nyc. streetsblog.org

to examples of a more egalitarian society that enables very diverse social exchanges.

However, during protests, it transforms according to special regulatory circumstances abrogating normal laws. Protest is disruptive of urban spatial relations, so law enforcement sometimes considers it a threat related to crime and terrorism. In some cases, the changes that local police had undergone bring them closer to military police as these images show.

For example, in April 2015, in response to the controversial "Spanish Citizen Safety Law"-that stated that it was is illegal to gather in front of government buildings without permission from authorities - Spanish activists group Holograms for Freedom organized the world's first ever virtual political demonstration. Holographic citizens holding placards appeared in front of the Spanish Congress to show that "they" were afforded greater freedoms than their real-life counterparts. ${ }^{6}$

\section{CITIZEN'S SECURITY PERCEPTION}

While policing cities can be seen as a normal and accepted phenomenon, military urbanism, when visible to the citizens is not. Policing, as Nicholas Blomely writes, regulates de internal life of a community, seeing to suppress threats of wellbeing. The sidewalk upon which the police perform is part of the public sphere. However military urbanism creates a series of isolate islands that not all the citizens can access. ${ }^{7}$
Referring to previous arguments, the way citizens feel about security is key as some governments and decision makers seems to assume argument that more security does justify less privacy. In a Report by DATA PSST and DCSS on "Public Feeling on Privacy, Security and Surveillance" published in November 2015 states that the British government and its intelligence agencies regularly invoke British public opinion addressing greater security, and; probably being prepared to give up privacy to enhance security. ${ }^{8}$

The European union is running a series of surveys and studies on their perception of security. The SurPRISE project has not only examined the idea that citizens seem to be willing to trade-off their privacy for enhanced security, but has also discussed the extent to which privacy infringing surveillance measures and technologies increase real security. The project explored alternatives where security can be achieved without compromising fundamental rights. Not surprisingly, the results of the study show that Europeans are not willing to compromise their privacy. "Participating citizens requested that the protection of privacy and personal data by updated regulations should be strictly enforced, both in the context of commercial and law enforcement activities. For this purpose, they demanded that authorities responsible for the protection of privacy should be equipped with sufficient resources. The implementation and use of surveillance-orientated security technologies (SOSTs) should be targeted and accompanied by proper and strict safeguards. The use of surveillance technologies should be justified and justifiable on a case-by-case basis; blanket mass surveillance is not accepted."

Plus, citizens stated that a comprehensive technology assessment involves a participative approach, and involving citizens in assessment and decision-making processes could be a solution. That is to say, good practices regarding technology necessarily involve social participation.

\section{THE AESTHETICS OF SECURITY}

As it has been previously stated, the security techniques that have traditionally been applied to public spaces have largely been based on policing or military-style approaches that seek to secure unsafe locations through robust physical interventions. Often such approaches are similar to commonly understood planning techniques such as "Secured by Design" or the already mentioned "Crime Prevention through Environmental Design." Both methods are based on the implementation of security cordons, barriers, and enhanced surveillance to seek to make spaces safer through the manipulation of the built environment in ways that reduce the attractiveness and physical access to possible targets. In practice, and faced with an escalating threat of urban terrorism, this has meant the mass use of security barriers, bollards, and high-visibility policing. ${ }^{10}$ 


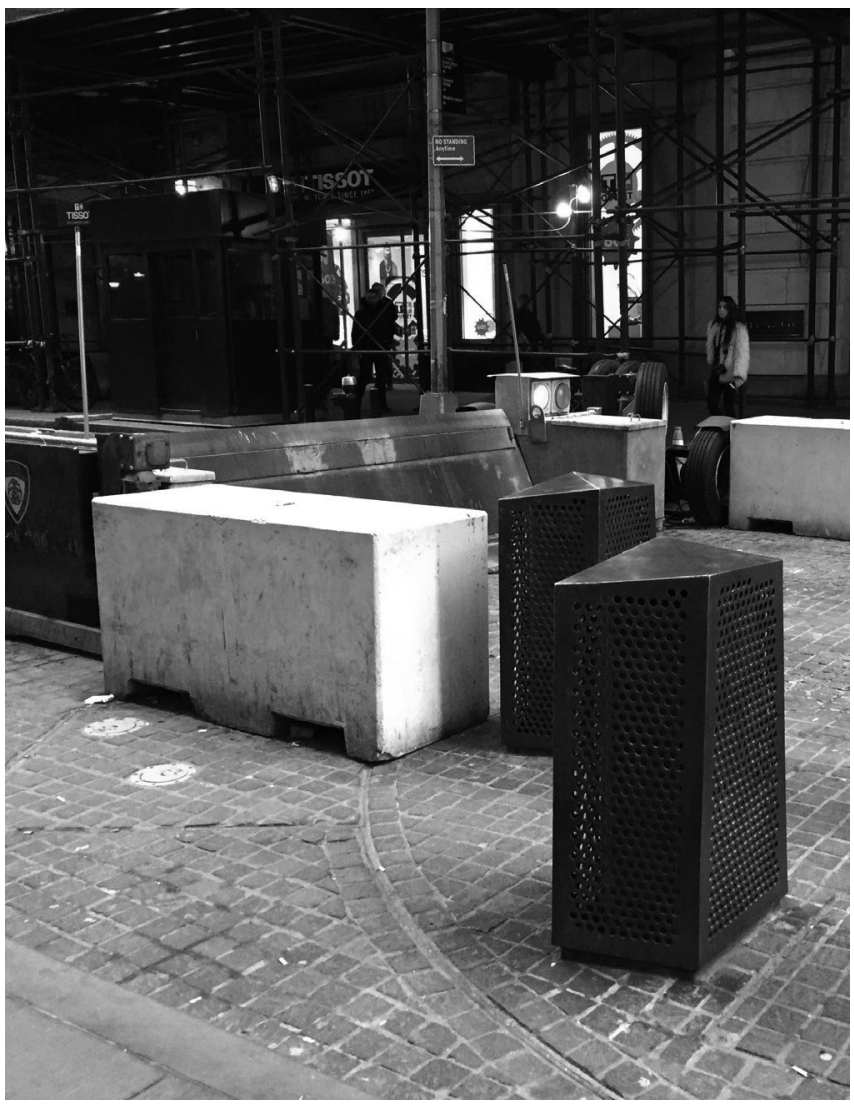

Figure 3: Designer bollards cohabitat with regullar jersey barriers in Wall Srteet. 2018. Photo: Maria Anton-Barco

Taking these physical and digital strategies and seeing how they have been implemented in Western cities allow us to try to identify good practices. The US FEMA 430 "Risk Management Series Site and Urban Design for Security Guidance Against Potential Terrorist Attacks," published in 2007 urged designers to "reduce the monotony of a long curbside barrier system" when designing safe perimeters. These kind of design guides and private advertisements have proliferated in the last years. ${ }^{11}$

However, these attempts have a downside. NYC blog shows how while trying to secure Times Square, the new barriers and police spots were implemented within the bike lane making this part of the city more dangerous for cyclist. While the 2007 FEMA manual already stated " the ubiquitous Jersey barrier is one of many devices used as perimeter security that, if not properly located, can degrade the quality and character of public space and severely detract from the sense of openness and accessibility that are features of an attractive and functional urban environment." 12

Following this advice some cities have tried to camouflage this security measures by redesigning these barriers, as the 6,700-pound bronze custom-art-formed security barriers designed to control vehicular traffic along Wall Street. A

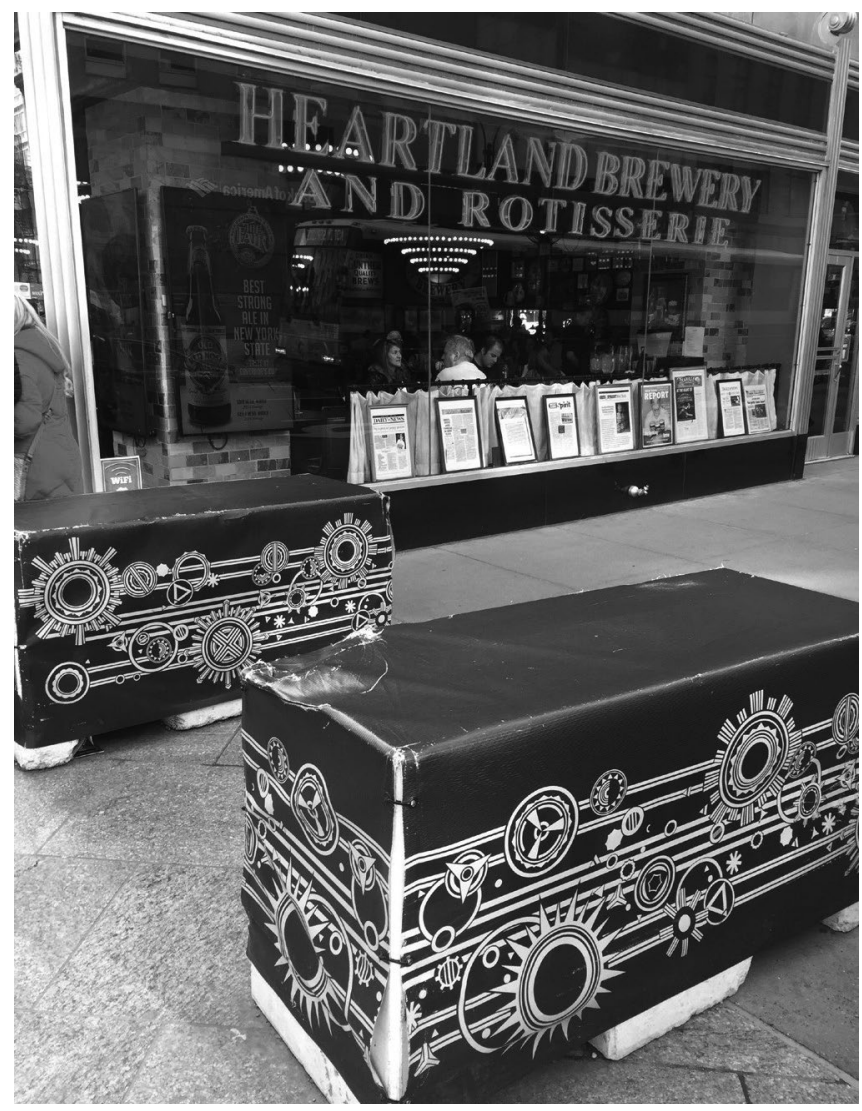

Figure 4: Jesey barriers covered in a plastics canvas in the surroundings of the Empire State Building. 2018. Photo: Maria Anton-Barco

cheaper strategy has been followed in the surroundings of the Empire State Building where the jersey barriers have been covered with a plastic printed canvas.

Following last years Barcelona attack, giant mobile plot plants where installed at Madrid's Puerta del Sol. While de vegetation soon died as a result of the extreme summer weather and lack of maintenance but the planters were used as improvised urban sitting in a public space where there is none.

Yet, another question arise: is the difference only a mere question of attractiveness?. FEMA's guide:

"Poor design or the wrong design details can inadvertently draw too much attention to the security design and make tenants and neighbors feel more vulnerable and threatened while the appropriate design can blend security into the existing streetscape or community without drawing attention to it and serve as amenities for tenants and neighbors." 13

Thus, architects and designers role for making spaces safer is limited to aesthetics? 

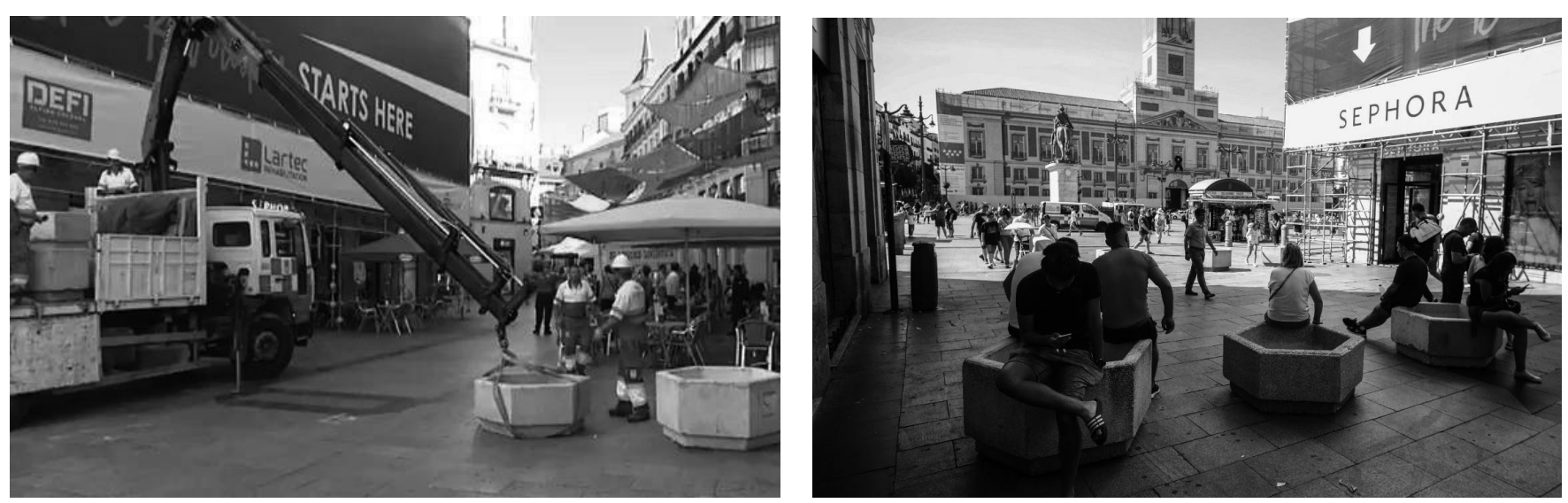

Figure 5: In summer 2017, after Barcelona attacks concrete planters were installed at Puerta del Sol.

\section{LESSONS FOR PRACTICE}

In the light of the new challenges cities are facing in terms of security we now wonder whether the city as a public space has disappeared in favor of a series of safe spaces. Security has yet to become more civic, urban, domestic and personal.

More than a decade after $9 / 11$ it is fair to say that when security measures come, they tend to stay. Although it is not clear that any security interventions have proved to be infallible, prevailing policies still consider that more is better.

An obsession with security is redefining the public realm and turning it into privately-owned public spaces. But this new normal has more to do with political decisions than public security agendas. Withal, good practices regarding these issues were hard to find and the role of the architect is yet to be defined.

\section{ENDNOTES}

1. Un-Habitat, United Nations, Human Settlements Programme Enhancing Urban Safety and Security: Global Report on Human Settlements. (2007).

2. Graham, Stephen. Cities Under Siege: The New Military Urbanism Verso (New York: Verso, 2011).

3. U.S. Secretary of State, Patterns of Global Terrorism 1998 (Washington, DC: U.S.).

4. Graham, Stephen. Cities Under Siege: The New Military Urbanism Verso (New York: Verso, 2011).

5. Graham (2011).

6. https://docubase.mit.edu/project/holograms-for-freedom/

7. Nicholas Blomley, The Borrowed View: Privacy, Propriety, and the Entanglements of Property In Law \& Social Inquiry. Vol. 30, No. 4 (Autumn, 2005), pp. 617-661.

8. DATA PSST and DCSS, Public Feeling on Privacy, Security and Surveillance (Cardiff: Cardiff University, November 2015).

9. Surprise Project. http://surprise-project.eu/

10. GCDN Commissioned Research, Beyond Concrete Barriers Innovation in Urban Furniture and Security in Public Space (2018).

11. FEMA 430, Risk Management Series Site and Urban Design for Security Guidance Against Potential Terrorist Attacks (2007). 4-31.

12. FEMA, 4-2.

13. FEMA, 3-15 